\title{
Adjustment Level of Post Graduate Science and Social Science in Relation to Their Gender
}

\author{
Lokanath S Puthanikar ${ }^{1} *$
}

\section{ABSTRACT}

The present study aimed to assess the level of adjustment of post-graduate science and social science students. It was hypothesized that post-graduate science students have lower adjustment than post-graduate social science students. It was also hypothesized that post-graduate social science male students have lower adjustment than post-graduate social science female students. Post-graduate science male students have lower adjustment than post-graduate science female students. In order to verify the above hypotheses a sample of 160 subjects with science and social-science background were selected from the Karnatak University Dharwad, Karnatak, India. Each group consist to 80 subjects with male $(\mathrm{N}=40)$ and female $(\mathrm{N}=40)$. To measure the adjustment, Adjustment Inventory developed and standardized by Asthana (1967) was administered individually, it has 42 items. The data were subjected to ' $t$ ' analyses and the major findings of the study revealed that the science post-graduate students have significantly higher level of adjustment than social-science post-graduate students. There is no significant difference between the male students of social science and science departments and also the female students of science departments. There is significant difference between the science male and science female students on adjustment pattern.

Keywords: Adjustment, Science Students, Social Science Students.

The present study aims at studying the level of adjustment among college students. Adjustment deals with various changes they handle during college life. In addition to the physical changes students experience a great deal of emotional and developmental changes too. Individuals decide to go to college or university for many reasons. For some it is a certificate, diploma or degree as a stepping-stone for a job or career. For many, it is a chance to learn new things, interact with new persons and there by a challenge for themselves with new experiences and ideas. College is a huge transition for most of the students, especially for fresher, it is a time for adjustment.

\footnotetext{
${ }^{1}$ Research Scholar, Department of Psychology, Karnatak University Dharwad

*Responding Author

(C) 2016 I L Puthanikar; licensee IJIP. This is an Open Access Research distributed under the terms of the Creative Commons Attribution License (http://creativecommons.org/licenses/by/2.0), which permits unrestricted use, distribution, and reproduction in any Medium, provided the original work is properly cited.
} 


\section{Adjustment Level of Post Graduate Science and Social Science in Relation to Their Gender}

\section{Adjustment of College Students:}

The shift between high school and college can be challenging and many changes occur in emotional, social and academic adjustment (Gerdes \& Mallinckrodt, 1994). Adjustment difficulties, loneliness and depression are much more common nowadays among college students than their peers who are not in college. Specifically, adjustment difficulties arise from unresolved family problems, the differences between the expectations and the realities of college, academic deficiencies, financial difficulties, and the lack of developing sufficient social support in the campus. When adjustment difficulties arise, many college students try to resolve such problems through unwise and sinful behaviors. A significant degree of our culture's dissatisfactions and disappointments with life, work and relationships are that we expect too much from them.

\section{Significance of Adjustment:}

The psychology of adjustment is in fact based on our concern with the quality of life, it focus on particular aspects of understanding one's self, understanding others and living in harmony with ourselves and others.

The adult moves through life building upon accomplishment of the stage just past confronting the task of the current stage and preparing for the future. A failure in mastering these tasks eventuates in personal unhappiness, disapproval of society, immaturity, incompetency, and consequent difficulties in mastering later developmental tasks. Thus the onward growth process may be crippled. Therefore it is necessary to gain a fair insight into the problem of adjustment of adults, in order they may be helped to deal effectively with the 'stress' strain that characterize uniquely this phase of development.

Studies on adjustment of adults are intended to enrich our understanding of the nature of adjustment in relation to some of the most important factors like intelligence, academic achievement, vocational interests and socioeconomic background. Understanding of adjustment of post-graduate students calls for the most direct and immediate interest of parents, psychologists, educationists as well as of those who are engaged in rendering counseling and guidance services to the students.

\section{Educational Adjustment:}

School is more than a place where culture is transmitted and skills being taught. It is a world of varied human contacts that demands adjustment on the part of child. It is a world where friendships are made and those who do not easily make friends feel isolated. They are not selfbound. Particularly, minority and economically less favored groups may feel lack of status and acceptance. Level of academic achievement during adolescence and educational attainment later in life are strong predictors of variety of indicators of well being in adulthood. A well-adjusted adolescent meets his/her college environment with the initiative of full sharing with others and for the optimum development of himself/ herself. Student's perceptions of their teachers' interest 


\section{Adjustment Level of Post Graduate Science and Social Science in Relation to Their Gender}

in their education also seem to have implications for their expected and aspired educational attainment.

\section{Definition:}

According to L. S. Shaffer (1961) "adjustment is the process by which living organism maintain a balance between its need and the circumstances that influence the satisfaction of these needs.”

For Eysenck (1972) “adjustment is a state in which the needs of the individual on the one hand and the claims of environment on the other hand are fully satisfied or the process by which this harmonious relationship can be attained.”

Smith (1961) defines "a good adjustment is one which is both realistic and satisfying. At least in the long run it reduces to minimum, the frustrations, the tensions and anxieties which a person must endure".

\section{REVIEW OF LITERATURE}

Agarwal (1970) investigated the problem of adjustments of college students in relation to various areas and sex of social science. Results using individual ' $t$ 'tests showed that: (a) arts students were better adjusted than science students, (b) girls were better adjusted than boys, and (c) adjustment of arts boys in the college adjustment area was poorest compared to other areas. Adjustment of arts girls was best in the home adjustment area but poor in the personal and health area.

Sharma (1978) conducted a study of factors underlying adjustment problem of professional and non-professional college students. The scope of study was limited to five adjustment areas home, school, health, educational and emotional. The study revealed that the non-professional college students had more problems than the professional college students in the area of home problems. The arts students had greater problems in home and health areas than the engineering students. The science students had greater problems in area of home than medical students. The aesthetic and social interest and socio-economic status contributed significantly towards the well adjustment of professional college students.

Armin Mahmoudi (2012) conducted study to see the adjustment level of the post-graduate students of Yasouj city. Emotional maturity was measured by Singh's emotional maturity Scale (EMS). While Asthenia's adjustment inventory was used to measure the adjustment level of the students. For this study a sample of 160 female students of age range 18-22years Studying in post graduate closes were selected from different colleges of Yasouj city. High positive correlation was obtained between emotional maturity and overall adjustment. .

Saxena (1978) examined the relationship between scholastic achievement and adjustment of 350 male students. Students were identified as over and under-achievers in four areas viz., 


\section{Adjustment Level of Post Graduate Science and Social Science in Relation to Their Gender}

Mathematics, Biology, Commerce and the Arts. Students were administered an adjustment inventory with five categories (home, health, social, emotional and school adjustment) and a total adjustment score. Under-achievers showed significantly poorer adjustment in the home, health and school areas, as well as in the overall adjustment. The relationship between adjustment and achievement was strongest for students in mathematics. In the arts group no significant differences were found.

Nirmaljit (1992) selected randomly 320 athletes (160 male and 160 female) from colleges and universities of Haryana and Union Territory of Chandigarh to conduct a study with regards to the adjustment as related to performance and gender in team sports. She used Sinha and Singh's Inventory (1980) to measure all the areas of adjustment. It was found that the university athletes were significantly different from the college athletes on social, emotional and overall adjustment. The male athletes from the studied team sports were found better adjusted than the female athletes from the same sports groups on all the adjustment variables except home adjustment in which the difference between the male and the female athletes was not significant.

Kanter et al., (2007) mentions that parents' influence on college students' adjustment is underestimated frequently. As college students often set goals based on their perceptions of their parents' expectations, discrepancies between college students' and their parents' expectations may be related to their adjustment. The purpose of this study was to examine parent-college student expectation discrepancies and communication reciprocity as predictors of college students' adjustment in a diverse sample of 69 male and 105 female freshmen and sophomores from a large southeastern university. A subsample of their mothers and fathers also participated in this study. Correlation results revealed that college students report experiencing lower levels of self-worth and adjustment when higher expectation discrepancies are present between themselves and their parents. Regression results also indicated that expectation discrepancies and college students' perceptions of communication reciprocity are important predictors of college students' self-worth and adjustment. Such findings suggested that teaching assertive communication skills to college students and their parents may serve as a means of promoting positive outcomes for college students.

Holmbeck and Wandrei (1993) assessed the differential predictive utility of home-leaving status, family functioning, separation-individuation issues, cognitive constructions of the home-leaving process, and personality variables for adjustment during the 1st year of college with a sample of 286 college freshmen (182 women and 104 men). Findings revealed that the separationindividuation, family relations, and personality variables were better predictors of adjustment than were the cognitive indicators or home-leaving status. Results also varied as a function of gender; less well-adjusted men were more disconnected from significant others, whereas less well-adjusted women exhibited higher levels of separation anxiety and enmeshment seeking. Implications for counseling interventions are discussed 


\section{Adjustment Level of Post Graduate Science and Social Science in Relation to Their Gender}

The findings of the study Paul M. Kyalo (2011) indicated that interpersonal relationships and the attitude of students towards university environment and academic programme were critical factors influencing social adjustment and academic adjustment of undergraduate students in the university. Both male and female students were exposed to the same environment that influenced their similar social and academic adjustment in the university. First year students have a higher level of academic adjustment compared to other students in the university. There is need for the university to increase the level of publicity of guidance and counseling services programme and its services in the universities so as to assist students un coping and adjusting to university life.

Kanter et al., (2007) mentions that parents' influence on college students' adjustment is underestimated frequently. As college students often set goals based on their perceptions of their parents' expectations, discrepancies between college students' and their parents' expectations may be related to their adjustment. The purpose of this study was to examine parent-college student expectation discrepancies and communication reciprocity as predictors of college students' adjustment in a diverse sample of 69 male and 105 female freshmen and sophomores from a large southeastern university. A subsample of their mothers and fathers also participated in this study. Correlation results revealed that college students report experiencing lower levels of self-worth and adjustment when higher expectation discrepancies are present between themselves and their parents. Regression results also indicated that expectation discrepancies and college students' perceptions of communication reciprocity are important predictors of college students' self-worth and adjustment. Such findings suggested that teaching assertive communication skills to college students and their parents may serve as a means of promoting positive outcomes for college students.

Estrada et al., (2006) study investigated the relationship between locus of control and social and personal-emotional adjustment to college life in students with and without learning disabilities (LD). Differences in locus of control in college students with and without LD were also examined. Results showed a significant relationship between locus of control and both social adjustment and personal-emotional adjustment for both groups. Students with external locus of control tended to have higher adjustment scores than others. No differences were found in the locus of control orientation between students with and without LD, and in the personal-emotional adjustment to college life. Students with LD scored higher in social adjustment than their peers without LD.

\section{RESEARCH METHODOLOGY}

\section{Research Problem:}

Problem of the present research is to study the adjustment of the post-graduate science and social science students in relation to their gender. 


\section{Adjustment Level of Post Graduate Science and Social Science in Relation to Their Gender}

\section{Objectives:}

The main objective of the present study is to measure the adjustment of post-graduate science and social science students in relation to their gender.

\section{Hypotheses:}

1. Post-graduate social science students have higher adjustment than post-graduate science students.

2. Post-graduate social-science male students have lower adjustment than post-graduate socialscience female students.

3. Post-graduate science male students have lower adjustment than post-graduate science female students.

\section{Sample:}

The sample of the present study consist total 160 subjects with two main groups are post graduate science students and post graduate social science students at Karnatak University Dharwad, Karnatak, India. Each group consist 80 subjects with male $(\mathrm{N}=40)$ and female $(\mathrm{N}=40)$. In order to verify the above hypotheses post-graduate students were selected post graduate science students from departments such as physics, mathematics, chemistry, botany, zoology, microbiology biochemistry respectively and post-graduate social science students from history, economics, political science, geography and social work departments. The samples include both male and female students.

\section{Tools:}

To measure the adjustment, Adjustment Quotient Inventory developed and standardized by Asthana (1967) was used, which has 42 items and measures. The inventory consists of two response 'YES' ( ) and 'NO' ( ) responses, the scoring of response was then carried out using the scoring key provided by test author.

The test-retest reliability studies indicated that there was consistency coefficient of 0.80 and this tool possesses content validity and face validity. The criterion group validity was established as 0.91 .

\section{Statistical Techniques:}

Obtained raw scores were converted into standard scores using 16.0 versions of SPSS, subsequently the mean and SD was calculated. The data was subjected to independent sample ' $t$ ' analysis to find the significant difference between the post-graduate science and social science students. 


\section{RESULTS AND DISCUSSION}

Table 01: Means, standard deviation scores and' $t$ ' value of the science and social science students on Adjustment.

\begin{tabular}{|c|c|c|c|c|}
\hline \multirow{2}{*}{\multicolumn{2}{|c|}{ VARIABLE }} & \multicolumn{2}{|l|}{ SAMPLE GROUP } & \multirow[b]{2}{*}{ 't' value } \\
\hline & & SCIENCE $(\mathrm{N}=\mathbf{8 0})$ & SOCIAL SCIENCE & \\
\hline \multirow{2}{*}{ ADJUSTMENT } & MEAN & 52.27 & 47.74 & \multirow{2}{*}{$2.93 * *$} \\
\hline & SD & 10.06 & 09.46 & \\
\hline
\end{tabular}

** Significant at 0.01 level.

Table 01 shows means, SD scores and ' $t$ ' value of the science and the social science students on adjustment. The results reveal that there is significant difference in the adjustment pattern between the science and the social science students. The science students have higher mean scores (52.27) than the social science students (47.74). The ' $t$ ' value obtained is 2.93, which is significant at 0.01 level. The mean scores reveal that the science students have a better adjustment than the social science students.

Table 02: Means, standard deviation and 't' value of the social science male and social science female students on adjustment.

\begin{tabular}{|c|c|c|c|c|}
\hline \multirow{2}{*}{\multicolumn{2}{|c|}{ Variable }} & \multicolumn{2}{|l|}{ Sample Group } & \multirow[b]{2}{*}{ 't' value } \\
\hline & & Social Science Male $(\mathrm{N}=\mathbf{4 0})$ & $\begin{array}{lll}\begin{array}{l}\text { Social } \\
(\mathrm{N}=40)\end{array} & \text { Science } & \text { Female } \\
\end{array}$ & \\
\hline \multirow{2}{*}{ Adjustment } & Mean & 46.16 & 49.31 & \multirow{2}{*}{1.50} \\
\hline & SD & 9.86 & 8.90 & \\
\hline
\end{tabular}

Table 02 shows means, SD scores and ' $t$ ' value of the social science male and the social science female students on adjustment. The results reveal that there is no significant difference in the adjustment pattern between the social science male and the social science female students. The social science male students have mean score of 46.16, whereas the social science female students have a mean score of 49.31. The ' $\mathrm{t}$ ' value obtained is 1.50 . This indicates that there is no significant difference between the social science male and social science female students on adjustment pattern.

Table 03: Means, standard deviation and ' $t$ ' value of the science male and science female students on adjustment.

\begin{tabular}{|l|l|l|l|l|}
\hline \multirow{2}{*}{ Variable } & \multicolumn{2}{|l|}{ Sample Group } & \multirow{2}{*}{ 't' value } \\
\cline { 3 - 4 } \multicolumn{2}{|l|}{} & Science Male (N=40) & Science Female (N=40) & \\
\hline \multirow{2}{*}{ Adjustment } & Mean & 55.48 & 50.06 & \multirow{2}{*}{$2.0^{*}$} \\
\cline { 2 - 4 } & SD & 11.15 & 08.41 & \\
\hline
\end{tabular}

* Significant at 0.05 level. 


\section{Adjustment Level of Post Graduate Science and Social Science in Relation to Their Gender}

Table 03 shows means, SD scores and ' $\mathrm{t}$ ' value of the science male and the science female students on adjustment. The results reveal that there is significant difference in the adjustment pattern between the science male and the science female students. The science male students have higher mean scores (55.48) than the science female students (50.06). The ' $t$ ' value obtained is 2.0,which is significant at 0.05 level. The mean scores reveal that the science male students have better adjustment than the science female students.

\section{CONCLUSION}

1. The science post graduate students have significantly higher level of adjustment than social science post graduate students.

2. There is no significant difference between the social science male and social science female students on adjustment pattern.

3. There is significant difference between the science male and science female students on adjustment pattern.

\section{REFERENCES}

Agarwal, Mahesh C.(1970). Adjustment among college students, Indian Psychological Review, 6(2), 85-87.

Armin Mahmoudi (2012).Emotional maturity and adjustment level of college students Education Research Journal, 2(1), 18 -19.

Dupoux, Errol; Wolman, Clara(2006). The Relationship between Locus of Control and PersonalEmotional Adjustment and Social Adjustment to College Life in Students with and without Learning Disabilities College Student Journal, 40(1), 43-54.

Eysenck, H.J. and others (1972): Encyclopedia of Psychology. Landon, Search Press, p.25

Gerdes, Hilary; Mallinckrodt, Brent.1994. Emotional, social, and academic adjustment of college students: A longitudinal study of retention, Journal of Counseling and Development, 72(3), 281-288.

Holmbek,G.N.\&Wandrei,M.L.(1993).Individual and relational predictors of adjustment in first year college students .Journal of Counseling Psychology,40,73-78.

Kanter et al., (2007). College Students' Adjustment: The Role of Parent-College Student Expectation Discrepancies and Communication Reciprocity J Youth Adolescence, 37:967-982.

Kanter et al., (2007). College Students' Adjustment: The Role of Parent-College Student Expectation Discrepancies and Communication Reciprocity J Youth Adolescence, 37:967-982.

Nirmaljit, K. (1992). “Team Cohesion, Adjustment And Achievement Motivation As Related To Performance And Gender In Team Sports", Unpublished Ph.D. Thesis, Punjab University, and Chandigarh.

Paul M. Kyalo (2011). Selected Factors Influencing Social And Academic Adjustment Of Undergraduate Students Of Egerton University; Njoro Campus, 2(18). 
Saxena, P.C. (1978). Adjustment Of Over and Under Achievers, Indian Journal of Psychometry and Education, 9, 25-33.

Shaffer L,S, (1961) . "The Psychology of Adjustment”( 2nd ed.), .Boston : Houghton Mifflin.

Sharma, G.R (1978). A study of factor underlying adjustment problems of professional and nonprofessional college students. Ph.D Thesis in Education, Merrut University.

Smith, H.C. (1961).Personality adjustment. New York: McGraw Hill Book Co.,175-200. 